\title{
Blends of Poly(ether ether ketone) with a Thermotropic Liquid Crystalline Polyester I. The Morphology, Crystallization, and Melting Behavior
}

\author{
Yang ZHONG, Jiarui Xu,* and Hanmin ZENG \\ Materials Science Institute, Zhongshan University, \\ Guangzhou, 510275, P. R. China
}

(Received July 8, 1991)

\begin{abstract}
Blends of poly(ether ether ketone) (PEEK) with a thermotropic liquid crystal copolyester (LCP-111), obtained by solution precipitation, were investigated by optical microscopy and differential scanning calorimetry. The as-precipitated blends underwent phase segregation on heating, as being evident by the microscopy observation. The phase morphologies, melting and crystallization behaviors of the blends were found to be affected by the LCP composition, showing smaller crystal size, slight depression of $T_{\mathrm{m}}$ and higher degree of crystallinity with increasing LCP content. When isothermally crystallized from the melt, a maximum overall rate of crystallization was found for the blend containing about $20 \mathrm{wt} \%$ of LCP. The results were discussed in terms of competition between the nucleation and dilution effects of LCP on the crystallization of PEEK.
\end{abstract}

KEY WORDS Blends / Poly (ether ether ketone)/ Liquid Crystal Copolyester

/ Phase Morphology / Crystallization/Melting Behavior/

Multicomponent polymeric systems containing a semicrystalline component have been investigated extensively in the literature. ${ }^{1-7}$ At temperatures sufficiently below the melting point of the crystallizable component, a separate crystalline phase can form, and the phase morphology, crystallization, and melting behavior of these systems have been found to be governed by a variety of factors such as miscibility, interaction between polymer segments, chain mobility, and processing history.

The concepts of "in situ composite" 8 and "molecular composite" 9 have led to a new class of polymeric blends in the last decade or so. Increasing interest in the properties of blends containing a liquid crystal polymer (LCP) component is being addressed, and a considerable body of research work detailing the process of phase separation, crystallization and melting of the blending system has been reported $^{6,7,10-13}$ Owing to the rigid rod nature of LCP molecules, the crystallizable component in the blend exhibited unusual crystallization and melting behavior compared with that of conventional blends. The presence of rigid LCP chain in these blend functions not only as reinforcing species, but also influences the morphology, crystallization kinetics, crystallinity, and melting of the crystallizable component. While the special properties of the LCP hold great promise for improved processing and enhanced strength of the blends, it is the crystalline phase which determines the ultimate solid-state properties of these materials.

In recent years, this laboratory has been actively pursuing investigations on the blends of high-performance thermoplastics such as poly(ether sulfone) (PES), poly(phenylene sulfide) (PPS) and poly(ether ether ketone) (PEEK). ${ }^{14-16}$ A series of thermotropic wholly

\footnotetext{
* To whom correspondence should be addressed.
} 
aromatic polyester is currently being used in the studies of composites and blends with other high-performance resins. Some previous work have shown that in the blend films cast from a PES/LCP solution with LCP being a minor composition, LCP acted as a nucleation agent to promote the formation of PES spherulites. ${ }^{17}$ It was also found that blending PPS with LCP enhanced the crystallization rate and affected the crystal morphology of PPS due to the nucleation of LCP component. ${ }^{18}$ Therefore, it is of interest to examine the effects of LCP on blends with PEEK which is a crystalline high-performance engineering thermoplastic with a large potential as advanced structural polymer materials. By blending with LCP, it is desirable that both improvement of processing property and reinforcement of mechanical strength of PEEK can be achieved. Those results will be reported in the separate publications. In this paper, the thermal transition process of PEEK in the blends obtained by solution precipitation was characterized and reported. The phase morphology and crystallization behavior as a function of composition were investigated and discussed.

\section{EXPERIMENTAL}

\section{Materials}

Poly(oxy-1,4-phenyleneoxy-1,4-phenylenecarbonyl-1,4-phenylene), commonly known as PEEK, used in this study is an ICI product (450P). The powder sample received was subject to purification by solution precipitation. The liquid crystal polymer (referred to below as LCP-111) is a thermotropic wholly aromatic copolyester of $p$-hydroxybenzoic acid, terephthalic acid, and resorcinol, kindly supplied by the Silicone Research Center, Chengdu, China. LCP-111 forms typical nematic texture from $300^{\circ} \mathrm{C}$ to $450^{\circ} \mathrm{C}$. The nematic texture can be readily reserved upon cooling. The LCP sample was also purified prior to use.

\section{Preparation of Blends}

Blends of PEEK/LCP-111 with different weight composition were obtained by means of solution precipitation. Purified PEEK and LCP-111 were first dissolved in $p$-chlorophenol (about 2\% wt/wt); the solution was then precipitated with methanol in a volume ratio of $1: 7$. The precipitate was dried in a vacuum oven at $70^{\circ} \mathrm{C}$ for over two weeks. Film samples for microscopy observation were prepared by direct solution casting followed by drying under vacuum.

\section{Differential Scanning Calorimetry}

The calorimetric measurements were carried out on a Perkin-Elmer DSC-2C calorimeter operating under nitrogen flow. The original precipitated samples were heated from room temperature to $380^{\circ} \mathrm{C}$ at a rate of $20^{\circ} \mathrm{C} \mathrm{min}^{-1}$, which is referred to below as the first heating run. For isothermal crystallization measurements, the samples were first heated to $380^{\circ} \mathrm{C}$ and hold at that temperature for 3 minutes, followed by cooling to $300^{\circ} \mathrm{C}\left(T_{\mathrm{c}}\right)$ at $-320^{\circ} \mathrm{Cmin}^{-1}$. The $T_{\mathrm{c}}$ selected is considered to be the temperature at which the crystallization rate and time can be fairly controlled. Samples after isothermal crystallization were used for the second heating runs. The nonisothermal crystallization process was recorded by cooling at a rate of $20^{\circ} \mathrm{C} \mathrm{min}^{-1}$ from $380^{\circ} \mathrm{C}$.

\section{Morphological Observation}

The morphologies of cast films were viewed by a LEITZ ORTHOPLAN polarizing microscopy equipped with a heating stage.

\section{RESULTS AND DISCUSSION}

The phase morphologies of PEEK/LCP-111 as a function of composition are shown in Figure 1. The micrographs were obtained from the cast films heated to $380^{\circ} \mathrm{C}$ for 15 minutes; hold at $300^{\circ} \mathrm{C}$ for 12 hours followed by cooling to the room temperature. It is expected that 

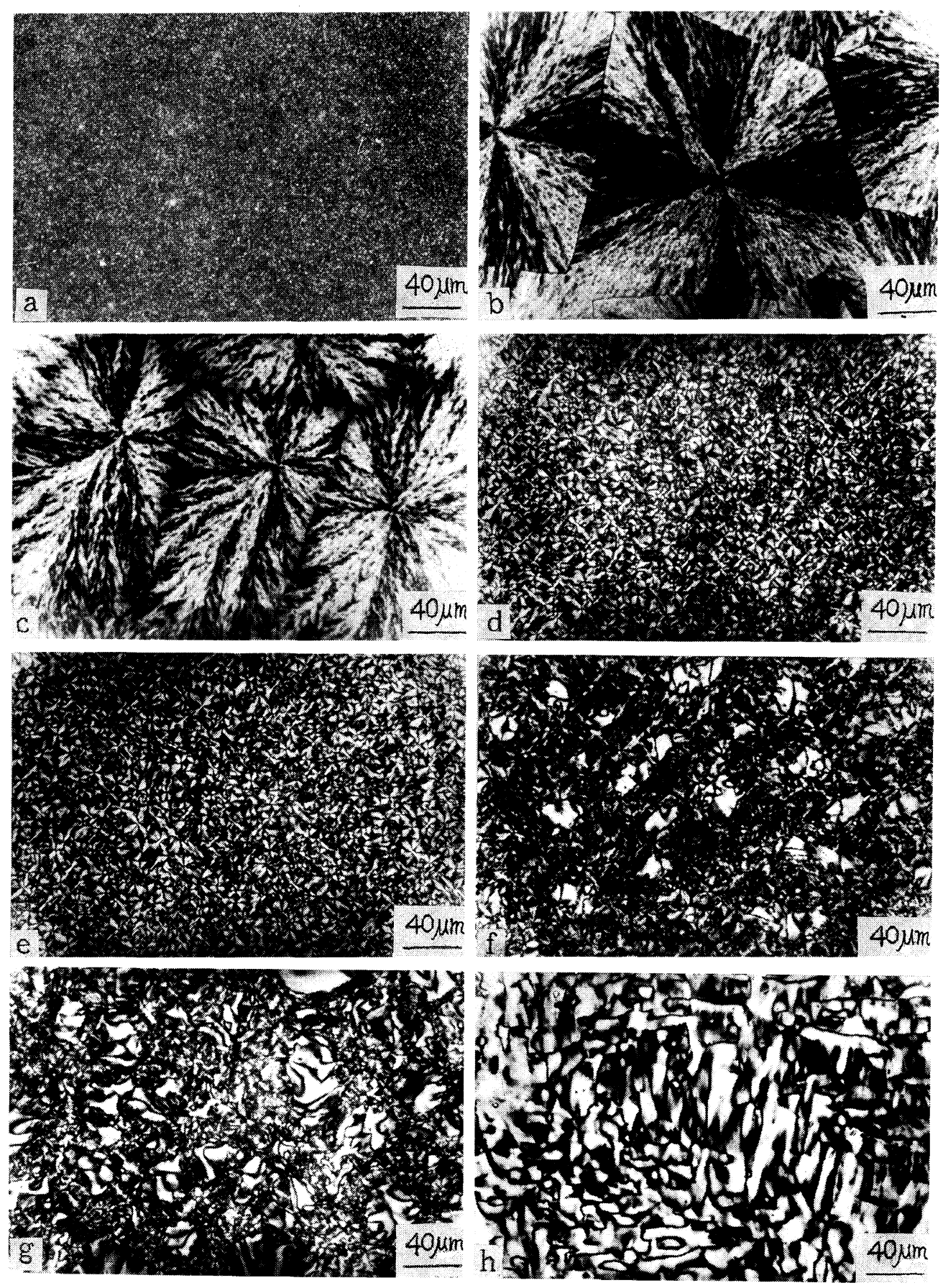

Figure 1. Optical micrographs. (a) LCP-111/PEEK 70/30 cast film; (b) - (h) LCP-111/PEEK blends crystallized from the melt at $T_{\mathrm{c}}=300^{\circ} \mathrm{C}$ for $12 \mathrm{~h}$ (crossed polarizers); (b) PEEK; (c) 10/90; (d) 30/70; (e) 50/50; (f) 70/30; (g) 90/10; (h) LCP-111. 
the state of molecular ordering of the two components in the as-cast films and in the films treated as above should be different. In the as-case films, molecules of PEEK and LCP were mixed homogeneously in their co-solvent. The phase separation, if occurring, would be caused mainly due to their solubility difference in the course of solvent vaporization upon drying. The phase domains presented in the film appeared to be tiny, well dispersed, and undistinguishable under optical microscope, as seen in Figure 1(a). When heated to $380^{\circ} \mathrm{C}$, which is about $30^{\circ} \mathrm{C}$ above the $T_{\mathrm{m}}$ of PEEK, the PEEK component should be in its isotropic melting state, while LCP was still in its nematic liquid-crystal phase. (The aromatic copolyester did not show an isotropic transition temperature before chemical decomposition at about $500^{\circ} \mathrm{C}$.) The system should thus exhibit a biphasic nature, namely a coexistence of anisotropic and isotropic phases. It is known that phase separation on heating is rather prevalent in polymetric blends and has been explained in the thermodynamic terms. ${ }^{19}$ To follow the segregating process, real time observation by optical microscopy for the blend during heating is currently under investigation.

Crystallization of PEEK furthered the phase separation process for the system. The morphology and size of the phase domains were found to depend strongly on composition and thermal history. It can be seen from Figure 1 that the size of PEEK spherulites decreased with increasing content of LCP. In general, the size of spherulites is governed by the number of nuclei formed. At the same $T_{\mathrm{c}}$, decrease in size reflects an increase in the population of nucleus. It is obvious that the addition of LCP increases the number of nucleation sites. Meanwhile, with the increase of LCP content, the concentration of PEEK in a unit volume decreased. To a certain point, the competition between the nucleation and dilution effects of LCP should ultimately reach an equilibrium, and the size of PEEK crystalline domain would not longer change significantly (see Figure 1(d) to $(\mathrm{g})$ ), For the blends with $50 \%$ LCP or higher, well grown spherulite was hardly found. This, however, does not necessarily imply a decrease in crystallinity. The effects of LCP component on the crystallization behavior and crystallinity of PEEK will be discussed in the later section.

On the other hand, LCP phase characterized by Schlieren texture became more and more apparent. For the 10/90 (LCP/PEEK) sample, it appeared that LCP was mainly located at the boundary between PEEK spherulites, as can be viewed in Figure 1(c). The edges of spherulites were not as smooth as that for pure PEEK sample (Figure 1(b)). Some LCP may also locate between the lamellar ribbons in the PEEK spherulites as different spherulitic appearance was seen (Figure 1(c)). However, $X$-ray diffraction study showed no change in the PEEK crystal structure of these samples. At higher content, LCP phase tended to segregate to form larger domains. One reason for this would be that the lower viscosity of LCP (as LCP was in its nematic state at that temperature) made it more movable.

DSC heating curves of PEEK, LCP-111 and their blends precipitated from solution, the first heating runs, are shown in Figure 2. Figure 3 shows the DSC heating curves for samples crystallized at $300^{\circ} \mathrm{C}$ and then heated again from the room temperature, the second heating runs. The phase transition parameters of both samples are summarized in Table I. Since the $T_{\mathrm{g}}$ values were all found intermediate between those of pure PEEK and pure LCP-111, it indicates that at least partial miscibility phenomena of PEEK and LCP-111 in the amorphous phase and/or an interfacial phase occurred as they were precipitated from the solution. The intermediate glass transition, however, became undetectable for the second heating runs. The $T_{\mathrm{g}}$ values obtained from those runs were all close to the $T_{\mathrm{g}}$ of pure PEEK, although they were scattered to some extent. This also suggests the occurrence of phase separation on heating, in coincidence 


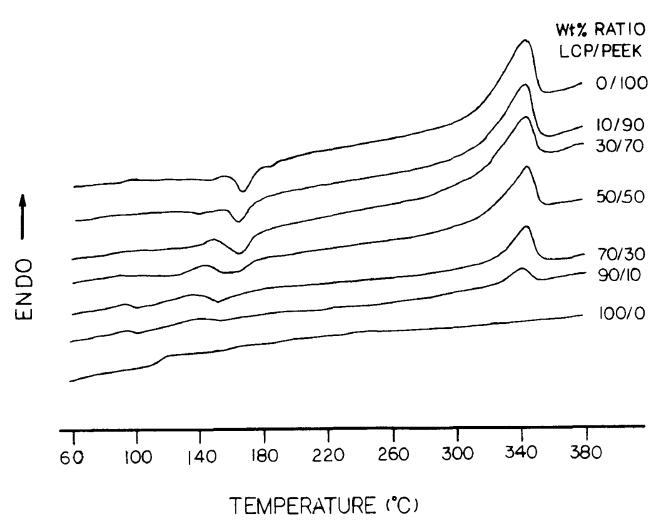

Figure 2. DSC curves in the first heating scan.

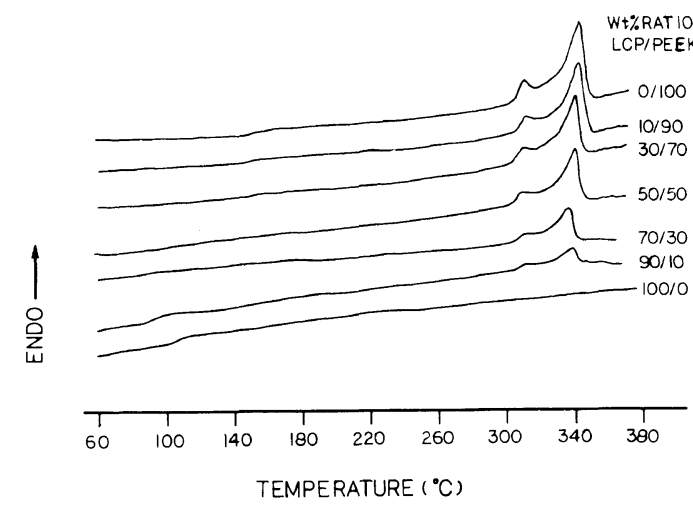

Figure 3. DSC curves in the second heating scan.

Table I. DSC results of LCP-111/PEEK precipitates ${ }^{\mathrm{a}}$

\begin{tabular}{|c|c|c|c|c|c|c|c|c|c|}
\hline \multirow{2}{*}{$\frac{\text { Samples }}{\text { LCP-111/PEEK }}$} & \multicolumn{4}{|c|}{ First heating scan } & \multicolumn{5}{|c|}{ Second heating scan } \\
\hline & $T_{\mathrm{g}} /{ }^{\circ} \mathrm{C}$ & $T_{\mathrm{m}} /{ }^{\circ} \mathrm{C}$ & $\Delta H_{\mathrm{m}} / \mathrm{Jg}^{-1}$ & $\Delta H_{\mathrm{m}}^{*} / \mathrm{Jg}^{-1}$ & $T_{\mathrm{g}} /{ }^{\circ} \mathrm{C}$ & $T_{\mathrm{m} 1} /{ }^{\circ} \mathrm{C}$ & $T_{\mathrm{m} 2} /{ }^{\circ} \mathrm{C}$ & $\Delta H_{\mathrm{m}} / \mathrm{Jg}^{-1}$ & $\Delta H_{\mathrm{m}}^{*} / \mathrm{Jg}^{-1}$ \\
\hline $0 / 100$ & 151.4 & 343.0 & 42.3 & 42.3 & 147.0 & 311.5 & 343.2 & 39.4 & 39.4 \\
\hline $10 / 90$ & 147.8 & 342.0 & 39.3 & 43.5 & 150.0 & 312.1 & 342.9 & 37.0 & 41.1 \\
\hline $30 / 70$ & 144.5 & 342.1 & 28.9 & 41.0 & 156.8 & 310.5 & 340.6 & 28.1 & 40.1 \\
\hline $50 / 50$ & 135.1 & 343.3 & 26.4 & 52.7 & 151.8 & 309.5 & 340.4 & 25.6 & 51.0 \\
\hline $70 / 30$ & 126.4 & 342.2 & 21.3 & 71.1 & - & 309.4 & 336.3 & 17.5 & 58.2 \\
\hline $90 / 10$ & 128.3 & 339.3 & 7.1 & 71.1 & - & 309.5 & 338.7 & 7.5 & 74.9 \\
\hline $100 / 0$ & 116.3 & - & - & - & - & - & - & - & - \\
\hline
\end{tabular}

a $\Delta H_{\mathrm{m}}$, heat of fusion of the blends; $\Delta H_{\mathrm{m}}^{*}$, heat of fusion based on the mass of PEEK in the blends; $T_{\mathrm{m} 1}$, lower endotherm; $T_{\mathrm{m} 2}$, Higher endotherm.

with the optical microscopy observation shown in Figure 1.

It is well known that blend showing phase separation on heating is generally considered as a metastable system, and the separating process is controlled by thermodynamic factors. ${ }^{20}$ For a substantially immiscible blend, the main factors important to the system are the spatial arrangement of phases (morphology) and the nature of interface between the phases. Although explanation of the separation process in more precise terms of thermodynamics and segmental interactions requires further studies, we may, however, conclude from the available experimental facts that this blend is also a metastable system, and its phase morphology is substantially influenced by the method and condition used to form the blend.

It can be seen from the DSC traces in Figure 2 and 3 that the melting behavior of the first and the second heating runs are quire different. For the first heating runs only a single peak was present, while the second heating runs show a double melting endotherm. The double endotherm has been explained as a combined result of continuous and recreystallization of PEEK crystals during the heating scan. ${ }^{21,22}$ Other experiments performed in this laboratory ${ }^{23}$ revealed that the low-melting peak would superpose with the high-melting peak as sufficiently high crystallization temperature, as also found by Cheng et al. ${ }^{22}$ It is thus likely that the low melting portion represents crystals of lower perfection, which were developed on 
cooling after completion of crystal growth at $T_{\mathrm{c}}$. The melting behavior of the precipitated sample, on the other hand, is much similar to that of quenched PEEK from the melt to liquid nitrogen (Figure 1 of ref 22). The difference is that crystals are still formed during precipitation for the precipitated samples because the cool crystallization peak of the first run curves is rather small compared with the melting endotherm (Figure 2).

Figure 4 plots the melting temperatures versus LCP composition. For the first heating runs, $T_{\mathrm{m}} \mathrm{s}$ showed little decrease except for the 90/10 sample. Depression of $T_{\mathrm{m}}$ was more obvious during the second scans, especially for the samples with higher LCP content $(>30 \%)$. At the experimental conditions used in this work, the LCP component gave no heat transition in the melting region of PEEK crystals, as being evident in Figures 2 and 3 . The heat of fusion recorded in the region is therefore attributed totally to the PEEK component. In Figure 5, heat of fusion $\left(\Delta H_{\mathrm{m}}\right)$ for both runs was plotted as a function of composition. Almost all the experimental values result higher than those calculated on the basis of linear relation, indicating an increase in the crystalline phase of the blends. In contrast, investigations of transitional and crystallization behavior for the miscible conventional blend systems with one crystallizable component ${ }^{24,25}$ have shown that the crystallinities (and the $\Delta H_{\mathrm{m}}$ recorded therewith) of such blends were somewhere below the linear relation corresponding to a fixed level of crystallinity that is based on the mass of crystallization species in the blend. The depression of $T_{\mathrm{m}}$ and the increase in crystallinity for the blends in this study therefore suggest the existence of contrary effects of LCP on the phase transition and crystallization of PEEK (see below).

The parameters relating to the crystallization process of the blends are listed in Table II. The $n$ values of Avrami equation obtained from the initial stage of isothermal crystallization at

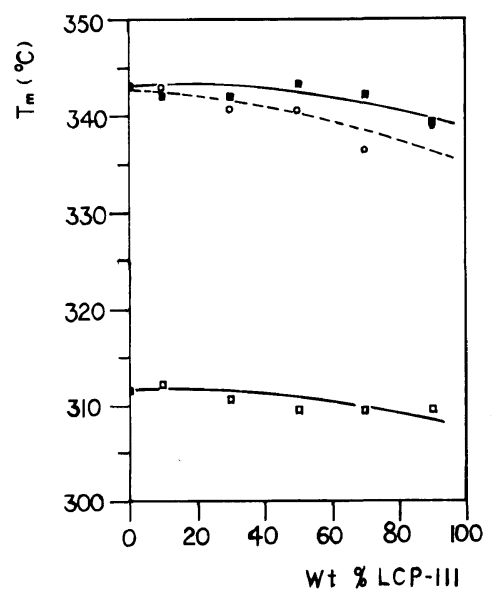

Figure 4. Plots of the melting temperature $T_{\mathrm{m}}$ versus composition. $\square, T_{\mathrm{m}}$ during the first heating scan; $\bigcirc$, higher endotherm $T_{\mathrm{m} 1}$ during the second heating scan; $\square$, lower endotherm $T_{\mathrm{m} 2}$ during the second heating scan $\left(20^{\circ} \mathrm{C}\right.$ $\min ^{-1}$ ).

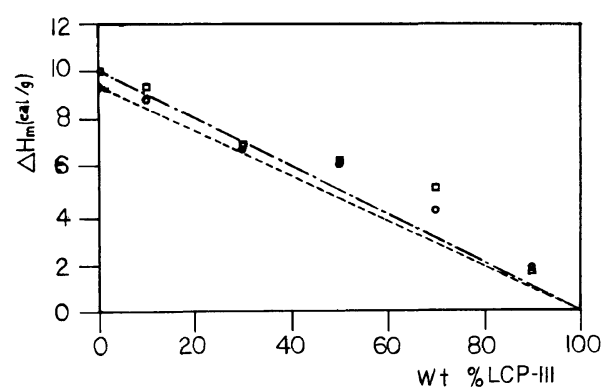

Figure 5. Plots of the heat of fusion $\Delta H_{\mathrm{m}}$ versus composition. $\square$, the first heating scan; $O$, the second heating scan. The dashed lines are that predicted by linear relation.

$300^{\circ} \mathrm{C}$ are between 2 to 3 except for the $90 / 10$ sample, suggesting the heterogeneous nucleation growth nature of these samples. In addition, the presence of LCP enhanced the overall crystallization rate for most of the samples. Generally, the time required for $50 \%$ of crystallinity, $t_{1 / 2}$, can be used as a measure of crystallization rate. Figure 6 shows the plots of $t_{1 / 2}$ values and degree of supercooling, $\Delta T$, versus LCP content, respectively. The values of $\Delta T$ were obtained by $T_{\mathrm{m}}-T_{\mathrm{c}}^{\mathrm{c}}$, and are relatively independent of the determination of $t_{1 / 2}$. It can 
Table II. Crystallization parameters of PEEK and blends with LCP-111 determined by DSC and Avrami equation

\begin{tabular}{cccccc}
\hline \multirow{2}{*}{$\begin{array}{c}\text { Samples } \\
\text { LCP- }\end{array}$} & \multicolumn{5}{c}{ Crystallization parameter } \\
\cline { 2 - 6 } $111 /$ PEEK & $T_{\mathrm{c}}^{\mathrm{c}} /{ }^{\circ} \mathrm{C}$ & $\begin{array}{l}\Delta H_{\mathrm{c}} / \\
\mathrm{Jg}^{-1}\end{array}$ & $\begin{array}{l}\Delta H_{\mathrm{c}}^{*} / \\
\mathrm{Jg}^{-1}\end{array}$ & $n$ & $\begin{array}{c}K \times 100 \\
/ \mathrm{min}^{-3}\end{array}$ \\
\hline $0 / 100$ & 281.0 & 40.2 & 40.2 & 2.5 & 16.6 \\
$5 / 95$ & 280.4 & 36.8 & 38.9 & 2.1 & 140.2 \\
$10 / 90$ & 289.5 & 37.2 & 41.4 & 2.1 & 122.5 \\
$20 / 80$ & 294.3 & 29.7 & 37.2 & 2.1 & 998.7 \\
$30 / 70$ & 280.1 & 30.1 & 43.1 & 2.3 & 32.4 \\
$50 / 50$ & 284.0 & 23.8 & 47.7 & 2.3 & 67.6 \\
$70 / 30$ & 271.6 & 14.6 & 49.0 & 2.5 & - \\
$90 / 10$ & 272.5 & 5.4 & 53.6 & 1.8 & 7.3
\end{tabular}

a $T_{\mathrm{c}}^{\mathrm{c}}$, crystallization temperature on cooling from $380^{\circ} \mathrm{C}$

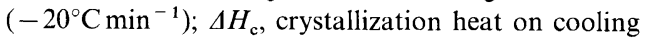
of the blends; $\Delta H_{\mathrm{c}}^{*}$, crystallization heat on cooling based on the mass of PEEK in the blends; $n$ and $K$, parameters in Avrami equation.

be noted that minima were found for both curves at the same composition around $20 \%$ of LCP. The overall crystallization rate generally reflects the competition between nucleation rate and the rate of transport or diffusion of polymer chains in the blends, and it is undoubtedly dependent on the blend composition, the structures of the polymeric components, and the conditions used to treat the samples. Adding of LCP component results in dilution of the crystallizable species and hindering the transport of PEEK chains, especially at higher LCP content. On the other hand, the rigid rod chain and/or the ordered microdomains (formed as in its nematic state) of LCP functions as heterogeneous nucleation agents. This is also supported, in addition to the rate data, by the facts that the size of PEEK crystals decreased as increasing LCP component discussed in the morphology section and that on cooling from the melt both the crystallization temperature $T_{\mathrm{c}}^{\mathrm{c}}$ (Table II) and crystallization heat $\Delta H_{\mathrm{c}}$ (shown in Figure 7) increased as increasing content of LCP as shown in Figure 7 . The detailed crystallization kinetic study for the blends is to be reported

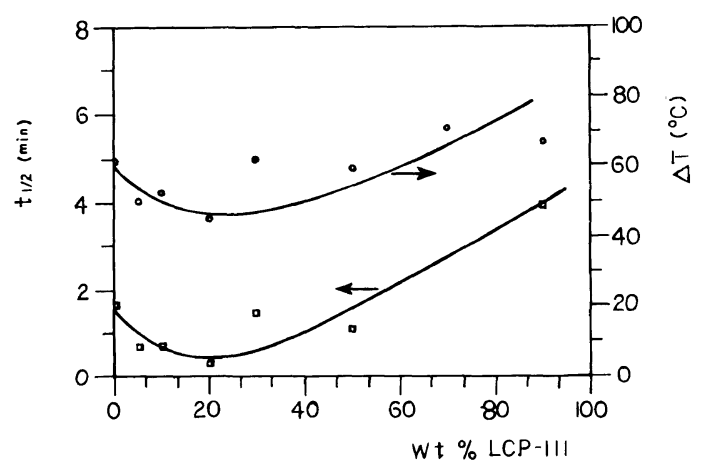

Figure 6. Plots of $t_{1 / 2}$ at $T_{\mathrm{c}}=300^{\circ} \mathrm{C}$ and $\Delta T$ versus composition. $t_{1 / 2}$, the half-time of crystalization from the melt; $\Delta T=T_{\mathrm{m}}-T_{\mathrm{c}}$ : the supercooling degree when cooling from $380^{\circ} \mathrm{C}$ at $-20^{\circ} \mathrm{Cmin}^{-1}$

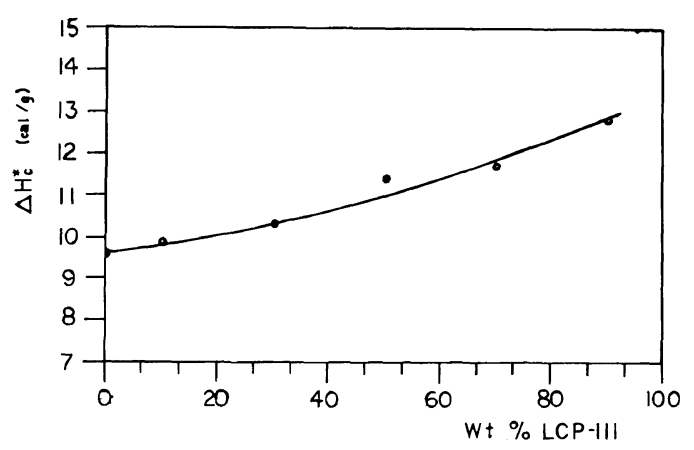

Figure 7. Plot of crystallization heat based on the mass of PEEK in the blends $\Delta H_{\mathrm{c}}^{*}$ when cooling from $380^{\circ} \mathrm{C}$ versus composition.

in the next paper.

Finally, the crystallinity of the blend, $X_{\mathrm{c}}$ was found to increase with LCP content. The results from the second DSC runs of the samples are plotted in Figure 8. The values of $X_{\mathrm{c}}$ can be calculated from:

$$
X_{\mathrm{c}}=\Delta H_{\mathrm{m}} / \Delta H_{\mathrm{m}}^{\mathrm{o}}(\mathrm{PEEK})
$$

where $\Delta H_{\mathrm{m}}^{\mathrm{o}}(\mathrm{PEEK})=130 \mathrm{~J} \mathrm{~g}^{-1}$ is the heat of fusion calculated for $100 \%$ crystalline PEEK. ${ }^{21}$ All the measured points are seen above the line predicted by linear relation. This increase in crystallinity can be too attributed to the nucleation effect of LCP, which results in more crystalline species of PEEK in the blends. It should be noted, however, that the crystallinity 


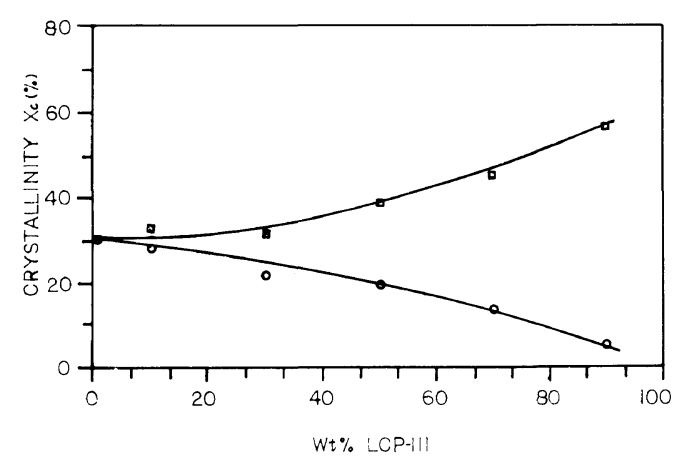

Figure 8. Plots of crystallinity versus composition. $\bigcirc$, based on the mass of the samples; $\square$, based on the mass of PEEK in the blends.

calculated in this way is an apparent value, and can only be considered a measure of the amount of crystalline phase, but not necessarily a description of perfection and regularity of the lamellas. For the blend with $90 \%$ of LCP the crystallinity calculated on the basis of PEEK mass seems higher than the highest crystallinity ever reported in the literature. ${ }^{26)} \mathrm{We}$ would not rule out the possible error from the normalization calculation because the quantity of PEEK in this sample was too small to measure its endotherm accurately.

\section{CONCLUSION}

Blends of semicrystalline PEEK and liquid crystalline aromatic copolyester, as obtained from solution precipitation, have been found to experience phase separation on heating. The coexistence of anisotropic (nematic) liquid crystalline phase and isotropic polymer phase showed great influences on the morphology, melting and crystallization behaviors of the blends cooled subsequently from the melt. It is believed that the presence of LCP caused both nucleation and dilution effects on the crystallization of PEEK component. These contrary effects increase with LCP content, and ultimately result in a maximum overall rate of crystallization at about $20 \%$ of LCP in the blend. In spite of the facts that the size of PEEK crystals became smaller and that the melting temperature of the blends depressed, the crystallinities of PEEK in the blends were found to increase with the addition of LCP.

Acknowledgement. The authors wish to gratefully acknowledge the financial support of the National Natural Science Foundation of China (Grant No. 9590015) and the National Educational Committee of China (Grant No. 9055811) on this work.

\section{REFERENCES}

1. T. Nishi and T. T. Wang, Macromolecules, 8, 909 (1975).

2. F. B. Khambatta, F. Warner, T. Russell, and R. S. Stein, J. Polym. Sci., Polym. Phys. Ed, 14, 1391 (1976).

3. G. Defieuw, G. Groeninckx, and H. Reynaers, Polymer, 30, 595 (1989).

4. G. Defieuw, G. Groeninckx, and H. Reynaers, Polymer, 30, 2158 (1989).

5. C. J. Ong and F. P. Price, J. Polym. Sci., Polym. Symp., 63, 45 (1978).

6. C. J. Ong and F. P. Price, J. Polym. Sci., Polym. Symp., 63, 59 (1978).

7. R. S. Stein and F. E. Khambatta, F. P. Warner, T. Russell, A. Escala, and E. Balizer, J. Polym. Sci., Polym. Symp., 63, 313 (1978).

8. G. Kiss, Polym. Eng. Sci., 27, 410 (1987).

9. M. Takayanagi, T. Ogata, M. Morikawa, and T. Kai, J. Macromol. Sci. Phys., B17, 591 (1980).

10. F. G. Joseph, G. L. Wilkes, and D. G. Baird, Polym. Sci. Technol., 28, 197 (1984).

11. M. Pracella, E. Chiellini, and D. Dainelli, Makromol. Chem., 190, 175 (1989).

12. S. K. Bhattacharya, A. Tendolkar, and A. Misra, Mol. Cryst. Liq. Cryst., 153 (Part A), 501 (1987).

13. G. D. Butzbach, J. H. Wendorff, and H. Zimmermann, Polymer, 27, 1337 (1986).

14. H. Zeng and C. Yang, in "Interfaces in Polymer, Ceramic and Metal Matrix Composites," H. Ishida, Ed., Elsevier Science Publishing Co., Amsterdam, 1988.

15. K. Mai and H. Zeng, Makromol. Chem., 187, 1787 (1986).

16. Z. Zhang and H. Zeng, "C-MRS International ' 90 Proceedings", Vol. 3, 1990, p 55.

17. J. Xu, W. Xian, and H. Zeng, Polym. Commun., 32, 336 (1991).

18. X. Zhou, J. Xu, and H. Zeng, to be published.

19. D. R. Paul, in "Multicomponent Polymer Materials", 
D. R. Paul and L. H. Sperling, Ed., ACS Advances in Chemistry Series, 211, 1986.

20. O. Olabasi, L. M. Robeson, and M. Shaw, in "Polymer-polymer Miscibility", Acedemic Press, New York, 1979, Chapter 2.

21. D. J. Blundell and B. N. Osborn, Polymer, 24, 953 (1983).

22. S. Z. D. Cheng, M. Y. Cao, and B. Wunderlich,
Macromolecules, 19, 1868 (1986).

23. Y. Zhong, J. Xu, and H. Zeng, results to be published.

24. D. R. Paul, J. W. Barlow, R. E. Bernsterin, and D.

C. Wahrmund, Polym. Eng. Sci., 18, 1225 (1978).

25. D. R. Paul and J. W. Balow, Polym. Sci. Technol., 11, 239 (1979).

26. R. B. Rigby, Polym. News, 9, 325 (1984). 